\title{
Depressive-Like Behavior Induced by Long-Term Ouabain Administration Accompanied Alteration in Neuroinflammation Parameters in Rats
}

Samira S. Valvassori ( $\sim$ samiravalvassori@unesc.net)

Unesc: Universidade do Extremo Sul Catarinense https://orcid.org/0000-0003-4824-7742

Jorge M. Aguiar-Geraldo

Unesc: Universidade do Extremo Sul Catarinense

Taise Possamai-Della

Unesc: Universidade do Extremo Sul Catarinense

Dayane D. da-Rosa

Unesc: Universidade do Extremo Sul Catarinense

\section{Samira Menegas}

Unesc: Universidade do Extremo Sul Catarinense

Gustavo C. Dal-Pont

Unesc: Universidade do Extremo Sul Catarinense

José H. Cararo

Unesc: Universidade do Extremo Sul Catarinense

João Quevedo

The University of Texas Health Science Center at Houston

\section{Research Article}

Keywords: Animal model of mania, bipolar disorder, inflammation, ouabain

Posted Date: December 30th, 2021

DOI: https://doi.org/10.21203/rs.3.rs-1146187/v1

License: (1) (1) This work is licensed under a Creative Commons Attribution 4.0 International License.

Read Full License 


\section{Abstract}

Objective: The present study aims to investigate the effects of Lithium ( $\mathrm{Li}$ ) on manic- and depressive-like behaviors and inflammatory parameters in rats submitted to the bipolar disorder (BD) model induced by ouabain (OUA).

Material and methods: Adult male rats received a single intracerebroventricular (ICV) injection of OUA or artificial cerebrospinal fluid (aCSF). On the fourth day after the ICV injection, the rats received intraperitoneal injections of saline $(\mathrm{NaCl} 0.9 \%)$ or $\mathrm{Li}(47.5 \mathrm{mg} / \mathrm{kg})$, two times a day, for 14 days. On the seventh day after OUA injection, the locomotor activity was assessed (open field test), and on the fourteenth day, locomotion was evaluated again, which was followed by the forced swimming test to evaluate depressive-like behavior. After euthanasia, inflammatory parameters were evaluated in the frontal cortex and hippocampus.

Results: After seven days of OUA administration, the animals showed a hyperactive behavior that was reversed by treatment with Li. After 14 days of ICV injections, rats exhibited a depressive behavior. Regarding the inflammatory parameters, measured after 14 days of the ICV infusions, OAU induced an increase in the levels of interleukin (IL)-1 $\beta$, IL-6, tumor necrosis factor $a$, and cytokine-induced neutrophil chemoattractant-1. In contrast, Li treatment decreased these parameters.

Conclusion: The animal model of BD induced by an OUA is able to induce neuroinflammation, which supports its construct validity for the BD research.

\section{Introduction}

Bipolar disorder (BD) is one of the most prevalent forms of mental illness comprising different mood shifts, ranging from episodes of mania or hypomania, depression, euthymia, and mixed states. ${ }^{1}$ Euphoria, expansive mood, high energy, psychomotor agitation or hyperactivity, and increased risk-taking behavior characterize the manic episodes, while deep sadness and anhedonia usually represent the depressive phase. ${ }^{2,3} \mathrm{BD}$ is a common and disabling condition associated with increased mortality in comparison to the general population, whose world prevalence rate stands at $1-2.5 \% .{ }^{4,5}$

Precise BD pathological mechanisms are not fully understood, but several biological systems were supposed to act perpetuating the condition. ${ }^{6}$ For example, oxidative stress, mitochondrial dysfunction, the release of inflammatory cytokines, and, consequently, the changes in ionic regulation channels can play a pivotal role in the pathophysiology. ${ }^{7-10}$ The advance in our understanding of BD pathophysiology can ultimately improve the therapeutic arsenal used for this condition. ${ }^{11}$

In this regard, lithium ( $\mathrm{Li}$ ) is a mood stabilizer drug used for more than 60 years, able to reduce acute symptoms of mania and also used in bipolar depression and BD maintenance therapy, avoiding new mood episodes. ${ }^{8,12}$ Studies have shown that Li induces widespread effects on different cellular 
pathways, with antioxidant, neuroprotective, and neurotrophic properties. ${ }^{13}$ Besides, the drug collaborates with the inflammatory system modulation in bipolar patients and animal models of mania. ${ }^{8,12}$

Research using animal models of psychiatric disorders has been relevant to unravel the pathophysiology of these conditions. ${ }^{14}$ To illustrate, research conducted with animal models of BD has helped to discover the pathways involved in its development. ${ }^{9}$ In this context, the present study uses as a platform the animal model of BD induced by the intracerebroventricular (ICV) administration of ouabain (OUA), a wellknown glycoside that inhibits the sodium/potassium adenosinetriphosphatase enzyme $\left(\mathrm{Na}^{+} / \mathrm{K}^{+}\right.$-ATPase; EC 3.6.3.9). ${ }^{15}$ Recently, the Valvassori and coworkers provided all validities required for a proper animal model of BD using this same platform since it mimics manic and depression behaviors in the same animal, as well as the alterations concerning pathophysiology and remission of the symptoms through traditional pharmacotherapy. ${ }^{16}$

Indeed, evidence has shown a significantly impaired $\mathrm{Na}^{+} / \mathrm{K}^{+}$-ATPase activity in bipolar patients in manic and depressive episodes. ${ }^{17}$ Additionally, recent research shows that this enzyme inhibition can lead to increased cytokine release, oxidative stress, immune response, and inflammation. ${ }^{17-20}$ Cytokines are small peptides and proteins responsible for cell interactions and are included in this class of molecules the cytokine-induced neutrophil chemoattractant 1 (CINC-1), interleukin(IL)-1 $\beta$, IL-6, IL-10, and tumor necrosis factor a (TNF-a). ${ }^{21} \mathrm{IL}-6$ is a multifunctional cytokine and a trophic factor for hybridoma and myeloma cells that mediates the transformation of activated B cells into antibody-synthesizing ones. ${ }^{22}$ IL-10 limits neuroinflammation by altering the resident glia and infiltrating leukocytes' response and by decreasing the synthesis of mediators by such cells. ${ }^{23} \mathrm{IL}-1 \beta$ is a potent pro-inflammatory cytokine mostly synthesized macrophages and other innate immune system cells, usually in response to the recognition of pathogen-associated molecular patterns by these cells. ${ }^{24}$ CINC-1 is a pro-inflammatory cytokine and a relevant chemoattractant to neutrophils, collaborating to infiltration of these cells in tissues. ${ }^{25} \mathrm{TNF}-\mathrm{a}$ is a pro-inflammatory mediator that drives immune pathways to prevent infiltration or damage to tissues and rules the survival or apoptosis of its target cells. ${ }^{26}$

Therefore, as an additional step towards a better insight on the proinflammatory imbalance of the disorder and validation of the BD model induced by OUA, the present study evaluates the behavior of rats and investigates the levels of important inflammatory mediators, i.e., IL-1 3 , IL-6, IL-10, CINC-1, and TNF- $a$ in the frontal cortex and hippocampus, seven and 14 days after a single ICV administration of the $\mathrm{Na}^{+} / \mathrm{K}^{+}$-ATPase inhibitor. Besides, it is also presented the Li effect in this experimental scenario.

\section{Material And Methods}

\section{Animals}

Thirty-two adult male Wistar rats (Rattus norvegicus, heterogenic strain), with 250-350 g body weight, were obtained from the breeding colony at the University of Southern Santa Catarina (UNESC). Animals 
were housed as five per cage, with ad libitum food and water and controlled conditions ( $12 \mathrm{~h}$-light/dark cycle; lights on at $6: 00$ a.m.; $22 \pm 1^{\circ} \mathrm{C}$ ). Experimental procedures started following approval by the UNESC's Ethical Committee on Animal Use for Research (record 66/2010), under the guidelines from the National Institutes of Health (US) "Guide for the Care and Use of Laboratory Animals" 27 and the Brazilian Society for Neuroscience and Behavior.

\section{Surgical procedure}

Animals were submitted to anesthesia by intramuscular injection of ketamine ( $80 \mathrm{mg} / \mathrm{kg}$ body weight) and xylazine $(10 \mathrm{mg} / \mathrm{kg})$ and accommodated in a stereotaxic apparatus, followed by removing the skin and hair covering the head. After this, it was placed a 27-gauge guide cannula $(9 \mathrm{~mm})$ on the surface of the cranial bone, according to the following coordinates: $0.9 \mathrm{~mm}$ posterior to bregma; $1.5 \mathrm{~mm}$ right from the midline; and $1 \mathrm{~mm}$ above the lateral brain ventricle. ${ }^{28}$ After marking, it was carrying out a $2 \mathrm{~mm}$ orifice on the animal skull, and a cannula was ventrally implanted $2.6 \mathrm{~mm}$ to the superior surface of the bone and fixed with dental acrylic cement.

Animals recovered from the procedure within three days, time in which they subcutaneously received tramadol hydrochloride ( $10 \mathrm{mg} / \mathrm{kg}$ body weight) each $12 \mathrm{~h}$ to mitigate the postoperative pain, by following the manufacturer's instructions (União Química Farmacêutica Nacional S. A., São Paulo, Brazil).

\section{Experimental design}

On the fourth day after the surgical procedure, a 30-gauge cannula was placed inside the guide cannula and linked to a microsyringe by using a polyethylene tube. The tip of the infusion cannula extended 1.0 $\mathrm{mm}$ beyond the guide cannula to reach the right lateral brain ventricle. Each animal received a single ICV injection of artificial cerebrospinal fluid (aCSF, $5 \mu \mathrm{L})$ or OUA $\left(10^{-3} \mathrm{M}\right)$ dissolved in aCSF $(5 \mu \mathrm{L})$. Each infusion lasted 30 seconds to prevent the liquid efflux. ${ }^{18,29}$ From the day following the aCSF or OUA injection, animals received intraperitoneal injections of saline (Sal, $1 \mathrm{~mL} / \mathrm{kg})$ or Li $(47.5 \mathrm{mg} / \mathrm{kg})$ twice a day, for 14 days. $^{30}$ Therefore, the rats were randomly assigned to four groups ( $n=8$ per group): 1 ) aCSF + Sal, 2) aCSF + Li, 3) OUA + Sal, and 4) OUA + Li (Figure 1).

\section{Behavioral}

The open field test occurred in two periods: seven and 14 days after ICV infusions, to provide insightful information on the locomotion, exploratory, risk-taking, and stereotypical behaviors of the animals. Briefly, the test ran in an apparatus with a $40 \mathrm{~cm} \times 60 \mathrm{~cm}$ floor surrounded by $50 \mathrm{~cm}$-high walls made of brown plywood with a frontal wall made of glass. The floor was divided into nine equal rectangles by black lines and covered with a glass base. Each animal was gently placed in the left rear rectangle to explore the 
arena for 5 minutes $(\mathrm{min})$. The hyperlocomotion indicates a manic-like behavior through the total number of crossings and rearings during the entire test period. ${ }^{31}$

\section{Forced swimming}

The procedure was carried out 13 days following ICV infusions to investigate animal immobility (total immobility or movements to keep the heads out of the water), which is a depressive-like behavior. The test occurred in two days of procedures, where each rat is placed in a cylinder with water $\left(23^{\circ} \mathrm{C}\right)$ in sufficient quantity so that it cannot support its paws on the bottom. On the first day, animals swam inside the apparatus for $15 \mathrm{~min}$ (training session). Twenty-four hours following training, the test session took place in which was assessed the times of swimming, climbing, and immobility for 5 min. ${ }^{32}$

\section{Biochemical analysis}

\section{Brain samples}

On the 14th day following OUA or aCSF infusion, after the behavioral tests, the rats were killed with a guillotine and the brain dissected to obtain the frontal cortex and hippocampus. Procedure occurred on a Petri dish placed on ice, followed by immersion of the samples in liquid nitrogen and subsequent storing at $-80^{\circ} \mathrm{C}$ for subsequent biochemical analysis.

\section{Neuroinflammation parameters}

Levels of TNF- $a$, IL-1 $\beta$, IL-6, IL-10, and CINC-1

The hippocampus and frontal cortex were homogenized in an extraction solution containing aprotinin (100 mg tissue per $1 \mathrm{~mL}$ ). The concentration of cytokines/chemokine was determined in the brain structures using commercially available ELISA assays, following instructions supplied by the manufacturer (DuoSet kits, R\&D Systems, MN, United States). Data are expressed as pg/100 mg tissue.

\section{Protein quantification}

Total protein was measured by the Lowry and coworkers' method, ${ }^{33}$ with slight modifications. ${ }^{34}$ Bovine serum albumin was used as a standard.

\section{Statistical analysis}

All data are present as mean \pm standard error of the mean. Variables were analyzed according to their distribution, with the Shapiro-Wilk's test for normality used for this purpose. Differences between groups determined by two-way analysis of variance (ANOVA) followed by Tukey's post hoc test. The software used in the analyzes was Statistica 7 (StatSoft, Inc., Tulsa, OK, United States). Differences were statistically significant as $p \leq 0.05$.

\section{Results}




\section{Behavioral analyses}

The open field test was performed to evaluate the rat locomotion. Assessed parameters included the number of crossings and rearings. Seven days after the rats received a single ICV injection of OUA, they presented a marked pattern of locomotion in comparison to aCSF group animals (Figure 2). $\mathrm{Li}$ administration reversed the increase in the crossings and rearings induced by OUA. Two-way ANOVA revealed significant OUA effects in the following seven days after ICV infusions [Crossings: $F(1,36)=$ 143.90, $p<0.05$; Rearings: $F(1,36)=71.61, p<0.05$ ] and treatment [Crossings: $F(1,36)=118.35, p<0.05$; Rearings: $F(1,36)=66.54, p<0.05$ ]

On the other hand, no significant differences between groups were observed in these parameters in the rats evaluated 14 days following OUA infusion [Crossings: $F(1,36)=10.02, p=0.003$; Rearings: $F(1,36)=$ $0.243, p=0.62$ ] and treatment [Crossings: $F(1,36)=0.22, p=0.640$; Rearings: $F(1,36)=0.007, p=0.93$ ] Thus, the evaluation of this behavior on the 14th after OUA injection revealed that rats did not exhibit the manic-like behavior as observed on the 7th day.

The next step of the behavioral assessments was the forced swimming test. In this context, it was demonstrated a significant increase in the time of immobility (in seconds) at 14 days following OUA administration. Besides, there was a significant decrease in the time of swimming (seconds) in rats in that same test. Altogether, these results demonstrate that after 14 days of OUA administration, the animals presented hopelessness, which is a depressive-like behavior. On the other hand, Li administration reversed the increase in immobility induced by OUA (Figure 2) [Immobility: $F(1,36)=301.06, p<0.05$; Swimming: $F(1,36)=301.06, p<0.05]$ and treatment [Immobility: $F(1,36)=301.06, p<0.05$; Swimming: $F(1,36)=301.06, p<0.05]$.

\section{Neuroinflammation parameters}

On the 14th day after OUA injection, the neurochemical measurements were conducted, with investigation of the effect of $\mathrm{Li}$ treatment in this experimental scenario. Data depicted in the following figures show significant alterations in the levels of IL-1 $\beta$ (Figure 3), IL-6 (Figure 4), IL-10 (Figure 5), TNF-a (Figure 6), and CINC-1 (Figure 7) in rats subjected to the animal model of BD induced by OUA. A single OUA administration elicited an increase in the levels of all inflammation parameters, regardless of cerebral structure, while Li administration prevented this alteration.

Data from two-way ANOVA revealed significant effects of OUA administration on the IL-1 $\beta$ levels [frontal cortex: $F(1,16)=30.95, p=0.002$; hippocampus: $F(1,16)=70.55, p<0.05$ ], as well treatment [frontal cortex: $F(1,16)=71.96, p<0.05$; hippocampus: $F(1,16)=67.94, p<0.05]$, and a significant OUA administration $\times \mathrm{Li}$ interaction [frontal cortex: $F(1,48)=45.24, p=0.15$; hippocampus: $F(1,47)=41.63, p<$ 0.05]. The same pattern of alterations was observed on the IL-6 levels regarding effect of OUA [frontal cortex: $F(1,16)=38.82, p=0.002$; hippocampus: $F(1,16)=32.12, p<0.05$ ], treatment [frontal cortex: $F(1,16)=69.34, p<0.05$; hippocampus: $F(1,16)=51.60, p<0.05]$, as well as a significant OUA 
administration $\times$ Li interaction [frontal cortex: $F(1,48)=49.31, p=0.15$; hippocampus: $F(1,47)=27.11, p<$ 0.05].

Additionally, a similar set of alterations was observed on the IL-10 levels, concerning to the effect of OUA [frontal cortex: $F(1,16)=15.09, p=0.001$; hippocampus: $F(1,16)=8.71, p=0.009$ ], treatment [frontal cortex: $F(1,16)=1.81, p=0.197$; hippocampus: $F(1,16)=17.17, p<0.05]$, as well as a OUA administration $\times$ Li interaction [frontal cortex: $F(1,48)=9.26, p=0.007$; hippocampus: $F(1,47)=19.38, p<0.05$ ] . The same pattern can be observed on the levels of TNF-a, regarding the effects of OUA [frontal cortex: $F(1,16)$ $=7.75, p<0.05$; hippocampus: $F(1,16)=33.73, p<0.05$ ], treatment [frontal cortex: $F(1,16)=1.81, p=$ 0.197; hippocampus: $F(1,16)=10.61, p<0.05$ ], as well the OUA administration $\times$ Li interaction [frontal cortex: $F(1,48)=19.06, p<0.05$; hippocampus: $F(1,47)=15.83, p<0.05]$. Finally, the CINC-1 levels followed the same pattern as demonstrated above, considering the effects of OUA [frontal cortex: $F(1,16)$ $=22.75, p<0.05$; hippocampus: $F(1,16)=7.71, p=0.013$ ], treatment [frontal cortex: $F(1,16)=17.02, p<$ 0.05; hippocampus: $F(1,16)=6.95, p=0.017$ ], and the OUA administration $\times$ Li interaction [frontal cortex: $F(1,48)=15.73, p=0.001$; hippocampus: $F(1,47)=15.11, p=0.001]$.

\section{Discussion}

Inflammation has been increasingly reported in the research focusing on the BD pathophysiology and therapy, both in clinical trials ${ }^{35,36}$ and animal studies. ${ }^{37}$ In bipolar patients, inflammatory mediators have been implicated in the disorder, potentially influencing the progression or severity. ${ }^{38,39}$ For instance, the cytokines whose levels are prone to an increase in BD patients, in comparison to healthy controls, include IL-4, IL-6, IL-10, and TNF-a. ${ }^{40}$ Additionally, the use of anti-inflammatory drugs as adjunctive therapy to mood stabilizers in the context of bipolar mania has demonstrated promising outcomes. ${ }^{35,37,41}$ Accordingly, it will be of great interest that a BD animal model, besides mimic the behavioral alterations of the disorder, also recapitulates the inflammatory alterations that may occur in bipolar patients, which highlights the need for further research in this field.

In this regard, the present study sought a better insight into the OUA model of BD, which was recently validated by the paper of Valvassori and coworkers. ${ }^{16}$ By corroborating data from these authors, the present study demonstrated that OUA administration induces an increase in the number of crossings and rearings seven days after OUA administration in rats, and these alterations are preventable by Li. Additionally, such alterations do not perpetuate until 14 days following the ICV infusions, while the forced swimming test showed a depressive-like behavior ("hopelessness") in the same animals at this period (also preventable by Li). Therefore, our behavioral findings reinforce the consistency of the OUA administration to model BD, which is a step forward to its validation. Indeed, in bipolar patients, manic episodes last at least seven days, while depressive symptoms are present within 14 days in the same subjects. ${ }^{2}$ This pattern is accurately represented in the OUA model. Besides the study carried out by Valvassori et al., ${ }^{16}$ our findings are similar to data provided by other papers, especially in the context of manic-like behaviors following injection of the $\mathrm{Na}^{+} / \mathrm{K}^{+}$-ATPase inhibitor. ${ }^{37,42,43}$ 
Moreover, the present study focused on the need to model the pro-inflammatory perspective of BD. ${ }^{10}$ To this aim, we measured the levels of relevant inflammatory mediators (IL-1 $\beta$, IL-6, IL-10, and TNFa) 14 days after OUA ICV infusions. In all parameters evaluated, OUA elicited a significant increase, while the Li administration reversed these alterations. Intriguingly, a similar study performed by our research group measuring the same cytokines did not find any alterations in these parameters, except IL-6, whose levels were decreased in the striatum of rats receiving OUA. ${ }^{21}$ Nonetheless, that paper investigated the OUA effect in an acute context, and here the findings are presented in a subchronic/chronic perspective, with the inclusion of the Li treatment for validation purposes. Data provided by our study mimic the inflammatory pathophysiological alterations reported in patients, ${ }^{44}$ which reinforces the validity of the model to simulate the pathophysiological aspects of the disorder. Further studies are required to unravel the precise mechanisms underlying these alterations in the inflammatory parameters. One possibility is that OUA can activate neuronal signaling pathways ruling the release of cytokines, such as the nuclear factor kappa B (NF-KB), which is activated by the glycoside according to prior studies. ${ }^{45,46}$ Also, NF-KB upregulation was detected in bipolar patients, potentially contributing to the pro-inflammatory balance of the disorder. ${ }^{47,48}$

One potential limitation of the present study is that $\mathrm{Na}^{+} / \mathrm{K}^{+}$-ATPase activity was not measured to confirm that OUA effects are related to an inhibition of this enzyme. However, this parameter was not altered by the glycoside in the Valvassori and coworkers' paper, ${ }^{16}$ which provided the experimental platform for the present study, although OUA is a well-known inhibitor. That study showed no inhibition on the 14th day after ICV infusion of the drug, time in which were carried out the measurements here. By regarding that the enzyme activity is pivotal for many neuronal roles, a stable decrease in this parameter might generate neurological disturbances, ${ }^{49,50}$ so that the protein can conform to the high OUA concentration to prevent disruption of its functions. Another possibility is the fact glycoside effect on the $\mathrm{Na}^{+} / \mathrm{K}^{+}$-ATPase may be independent on the ion transport activity of the protein; instead, the drug can activate a signaling complex comprising the enzyme, cluster determinant 36 (CD36), and Toll-like receptor 4, subsequently triggering inflammation driven by NF-кB. ${ }^{46}$

It is worthy to note that experiments from the present study timely mimicked the behavioral alterations of the disorder (face validity), as well as its pathophysiological inflammatory alterations (construct validity). Additionally, Li, a standard drug in BD therapy, was able to mitigate the behavioral and pathophysiological alterations induced in the model (predictive validity), which is the final criterion to validate OUA administration as a BD model.

In summary, OUA elicited a manic-like behavior seven days after its ICV administration, which was followed by depressive-like alterations several days later. Additionally, this drug induced an increase in all measured inflammatory mediators (IL-1 3, IL-6, IL-10, and TNFa) 14 days after ICV infusions. Li administration alleviated or reversed all these disturbances in behavior and neurochemistry, indicating that OUA administration is a valid model to study neuroinflammation in the context of BD. Since some 
cytokines are also significantly altered in bipolar patients, this experimental model might be useful to the screening of drug candidates for the therapy of this condition.

\section{Fouding}

Translational Psychiatry Program (USA) is funded by a grant from the National Institute of Health/National Institute of Mental Health (1R21MH117636-01A1, to JQ). Center of Excellence on Mood Disorders (USA) is funded by the Pat Rutherford Jr. Chair in Psychiatry, John S. Dunn Foundation and Anne and Don Fizer Foundation Endowment for Depression Research. Translational Psychiatry Laboratory (Brazil) is funded by grants from Conselho Nacional de Desenvolvimento Científico e Tecnológico (CNPq), Coordenação de Aperfeiçoamento de Pessoal de Nível Superior (CAPES), Fundação de Apoio à Pesquisa e Inovação do Estado de Santa Catarina (FAPESC), and Instituto Cérebro e Mente.

\section{Declarations}

\section{Fouding}

Translational Psychiatry Program (USA) is funded by a grant from the National Institute of Health/National Institute of Mental Health (1R21MH117636-01A1, to JQ). Center of Excellence on Mood Disorders (USA) is funded by the Pat Rutherford Jr. Chair in Psychiatry, John S. Dunn Foundation and Anne and Don Fizer Foundation Endowment for Depression Research. Translational Psychiatry Laboratory (Brazil) is funded by grants from Conselho Nacional de Desenvolvimento Científico e Tecnológico (CNPq), Coordenação de Aperfeiçoamento de Pessoal de Nível Superior (CAPES), Fundação de Apoio à Pesquisa e Inovação do Estado de Santa Catarina (FAPESC), and Instituto Cérebro e Mente.

\section{Acknowledgements}

We thank to National Institute of Health/National Institute of Mental Health, Pat Rutherford Jr. Chair in Psychiatry, John S. Dunn Foundation, Anne and Don Fizer Foundation Endowment for Depression Research, CNPq, CAPES, FAPESC and Instituto Cérebro e Mente. JQ and SSV are CNPq Research Fellows.

\section{Author Contributions}

All authors contributed to the study conception and design. Samira S. Valvassori and João Quevedo contributed to design and development; methodological design; supervision (responsible for organizing and executing the project and writing the manuscript); analysis/interpretation; literature survey; writing and critical review. Jorge M. Aguiar-Geraldo, Taise Possamai-Della, Dayane D. da-Rosa, Samira Menegas, Gustavo C. Dal-Pont and José H. Cararo participated data collection and processing; biochemical analyzes of the samples as well as performed statistical analyzes; analysis / interpretation; literature survey and writing.

\section{Data availability}


All data generated or analysed during this study are included in this published article.

\section{Ethics Approval}

Experimental procedures started following approval by the UNESC's Ethical Committee on Animal Use for Research (record 66/2010), under the guidelines from the National Institutes of Health (US) "Guide for the Care and Use of Laboratory Animals" and the Brazilian Society for Neuroscience and Behavior.

\section{Conflicts of Interests}

JQ received clinical research support from LivaNova; has speaker bureau membership with Myriad Neuroscience, Janssen Pharmaceuticals, and Abbvie; is stockholder at Instituto de Neurociencias Dr. Joao Quevedo; and receives copyrights from Artmed Editora, Artmed Panamericana, and Elsevier/Academic Press. All the other authors have no conflicts of interest.

\section{Consent to Participate}

Not applicable

\section{Consent for Publication}

All authors have agreed to the submission to Molecular Neurobiology.

\section{References}

1. Grande I, Berk M, Birmaher B, Vieta E (2016) Bipolar disorder. Lancet 387(10027):1561-1572. https://doi.org/10.1016/S0140-6736(15)00241-X

2. American Psychiatric Association (2013) Diagnostic and Statistical Manual of Mental Disorders (DSM-5®), 5th edn. American Psychiatric Publishing, Washinton (DC), p 991

3. Beyer DKE, Freund N (2017) Animal models for bipolar disorder: from bedside to the cage. Int J Bipolar Disorder 5(1):35. https://doi.org/10.1186/s40345-017-0104-6

4. Merikangas KR, Jin R, He JP, Kessler RC, Lee S, Sampson NA, Viana MC, Andrade LH, Hu C, Karam EG, Ladea M, Medina-Mora ME, Ono Y, Posada-Villa J, Sagar R, Wells JE, Zarkov Z (2011) Prevalence and correlates of bipolar spectrum disorder in the world mental health survey initiative. Arch Gen Psychiatry 68(3):241-251. https://doi.org/10.1001/archgenpsychiatry.2011.12

5. Hayes JF, Marston L, Walters K, King MB, Osborn DPJ (2017) Mortality gap for people with bipolar disorder and schizophrenia: UK-based cohort study 2000-2014. Br J Psychiatry 211(3):175-181. https://doi.org/10.1192/bjp.bp.117.202606

6. Muneer A (2016) The Neurobiology of Bipolar Disorder: An Integrated Approach. Chonnam Med J 52(1):18-37. https://doi.org/10.4068/cmj.2016.52.1.18

7. Anderson G, Maes M (2015) Bipolar disorder: role of immune-inflammatory cytokines, oxidative and nitrosative stress and tryptophan catabolites. Curr Psychiatry Rep 17(2):8. 
https://doi.org/10.1007/s11920-014-0541-1

8. Won E, Kim YK (2017) An Oldie but Goodie: Lithium in the Treatment of Bipolar Disorder through Neuroprotective and Neurotrophic Mechanisms. Int J Mol Sci 18(12):2679.

https://doi.org/10.3390/ijms18122679

9. Mack AA, Gao Y, Ratajczak MZ, Kakar S, El-Mallakh RS (2019) Review of animal models of bipolar disorder that alter ion regulation. Neurosci Biobehav Rev 107:208-214. https://doi.org/10.1016/j.neubiorev.2019.09.016

10. Benedetti F, Aggio V, Pratesi ML, Greco G, Furlan R (2020) Neuroinflammation in Bipolar Depression. Front Psychiatry 11:71. https://doi.org/10.3389/fpsyt.2020.00071

11. Kim Y, Santos R, Gage FH, Marchetto MC (2017) Molecular Mechanisms of Bipolar Disorder: Progress Made and Future Challenges. Front Cell Neurosci 11:30. https://doi.org/10.3389/fncel.2017.00030

12. Machado-Vieira R, Zanetti MV, Otaduy MC, De Sousa RT, Soeiro-de-Souza MG, Costa AC, Carvalho AF, Leite CC, Busatto GF, Zarate CA Jr, Gattaz WF (2017) Increased Brain Lactate During Depressive Episodes and Reversal Effects by Lithium Monotherapy in Drug-Naive Bipolar Disorder: A 3-T 1HMRS Study. J Clin Psychopharmacol 37(1):40-45. https://doi.org/10.1097/JCP.0000000000000616

13. Dell'Osso L, Del Grande C, Gesi C, Carmassi C, Musetti L (2016) A new look at an old drug: neuroprotective effects and therapeutic potentials of lithium salts. Neuropsychiatr Dis Treat 12:1687-1703. https://doi.org/10.2147/NDT.S106479

14. Howland JG, Greenshaw AJ, Winship IR (2019) Practical Aspects of Animal Models of Psychiatric Disorders. Can J Psychiatry 64(1):3-4. https://doi.org/10.1177/0706743718771833

15. Yu HS, Kim SH, Park HG, Kim YS, Ahn YM (2011) Intracerebroventricular administration of ouabain, a $\mathrm{Na}$ /K-ATPase inhibitor, activates tyrosine hydroxylase through extracellular signal-regulated kinase in rat striatum. Neurochem Int 59(6):779-786. https://doi.org/ 10.1016/j.neuint.2011.08.011

16. Valvassori SS, Dal-Pont GC, Resende WR, Varela RB, Lopes-Borges J, Cararo JH, Quevedo J (2019) Validation of the animal model of bipolar disorder induced by Ouabain: face, construct and predictive perspectives. Transl Psychiatry 9(1):158. https://doi.org/10.1038/s41398-019-0494-6

17. Banerjee U, Dasgupta A, Rout JK, Singh OP (2012) Effects of lithium therapy on Na+-K+-ATPase activity and lipid peroxidation in bipolar disorder. Prog Neuropsychopharmacol Biol Psychiatry 37(1):56-61. https://doi.org/10.1016/j.pnpbp.2011.12.006

18. Riegel RE, Valvassori SS, Elias G, Réus GZ, Steckert AV, de Souza B, Petronilho F, Gavioli EC, DalPizzol F, Quevedo J (2009) Animal model of mania induced by ouabain: Evidence of oxidative stress in submitochondrial particles of the rat brain. Neurochem Int 55(7):491-495. https://doi.org/10.1016/j.neuint.2009.05.003

19. Cavalcante-Silva LHA, Lima ÉA, Carvalho DCM, de Sales-Neto JM, Alves AKA, Galvão JGFM, da Silva JSF, Rodrigues-Mascarenhas S (2018) Much More than a Cardiotonic Steroid: Modulation of Inflammation by Ouabain. Front Physiol 8:895. https://doi.org/10.3389/fphys.2017.00895. Erratum in: Front Physiol. 2018 Jan 12;9:1 
20. Blaustein MP, Hamlyn JM (2020) Ouabain, endogenous ouabain and ouabain-like factors: The $\mathrm{Na}^{+}$ pump/ouabain receptor, its linkage to NCX, and its myriad functions. Cell Calcium 86:102159. https://doi.org/10.1016/j.ceca.2020.102159

21. Tonin PT, Valvassori SS, Lopes-Borges J, Mariot E, Varela RB, Teixeira AL, Quevedo J (2014) Effects of ouabain on cytokine/chemokine levels in an animal model of mania. J Neuroimmunol 276(12):236-239. https://doi.org/10.1016/j.jneuroim.2014.09.007

22. Tanaka T, Kishimoto T (2014) The biology and medical implications of interleukin-6. Cancer Immunol Res 2(4):288-294. https://doi.org/10.1158/2326-6066.CIR-14-0022

23. Burmeister AR, Marriott I (2018) The Interleukin-10 Family of Cytokines and Their Role in the CNS. Front Cell Neurosci 12:458. https://doi.org/10.3389/fncel.2018.00458

24. Lopez-Castejon G, Brough D (2011) Understanding the mechanism of IL-1 $\beta$ secretion. Cytokine Growth Factor Rev 22(4):189-195. https://doi.org/10.1016/j.cytogfr.2011.10.001

25. Tanaka Y, Kuwahara A, Ushigoe K, Yano Y, Taniguchi Y, Yamamoto Y, Matsuzaki T, Yasui T, Irahara M (2017) Expression of cytokine-induced neutrophil chemoattractant suppresses tumor necrosis factor alpha expression and thereby prevents the follicles from undergoing atresia and apoptosis. Reprod Med Biol 16(2):157-165. doi: 10.1002/rmb2.12022

26. Tian T, Wang M, Ma D (2014) TNF-a, a good or bad factor in hematological diseases? Stem Cell Investig. https://doi.org/10.3978/j.issn.2306-9759.2014.04.02. 1:12

27. National Research Council (US) (2011) Committee for the Update of the Guide for the Care and Use of Laboratory Animals. Guide for the Care and Use of Laboratory Animals, 8th edition. https://www.ncbi.nlm.nih.gov/books/NBK54050/. (Accessed October 19, 2020)

28. Paxinos G, Watson C (2013) The Rat Brain in Stereotaxic Coordinates: Hard Cover Edition. Academic Press, Cambridge (MA), p 472

29. el-Mallakh RS, Wyatt RJ (1995) The Na,K-ATPase hypothesis for bipolar illness. Biol Psychiatry 37(4):235-244. https://doi.org/10.1016/0006-3223(94)00201-D

30. Jornada LK, Moretti M, Valvassori SS, Ferreira CL, Padilha PT, Arent CO, Fries GR, Kapczinski F, Quevedo J (2010) Effects of mood stabilizers on hippocampus and amygdala BDNF levels in an animal model of mania induced by ouabain. J Psychiatr Res 44(8):506-510. https://doi.org/10.1016/j.jpsychires.2009.11.002

31. Broadhurst PL (1960) Experiments in psychogenetics: Application of biometrical genetics to the inheritance of behavior. In: Eisenk HJ (ed) Experiments in Personality: Psychogenetics and psychopharmacology. Routledge \& Kegan Paul, London, pp 31-71

32. Porsolt RD, Bertin A, Jalfre M (1977) Behavioral despair in mice: a primary screening test for antidepressants. Arch Int Pharmacodyn Ther 229(2):327-336

33. Lowry OH, Rosebrough NJ, Farr AL, Randall RJ (1951) Protein measurement with the Folin phenol reagent. J Biol Chem 193(1):265-275 
34. Peterson GL (1977) A simplification of the protein assay method of Lowry which is more generally applicable. Anal Biochem 83(2):346-56. https://doi.org/10.1016/0003-2697(77)90043-4

35. Edberg D, Hoppensteadt D, Walborn A, Fareed J, Sinacore J, Halaris A (2018) Plasma C-reactive protein levels in bipolar depression during cyclooxygenase-2 inhibitor combination treatment. $J$ Psychiatr Res 102:1-7. https://doi.org/10.1016/j.jpsychires.2018.02.004

36. Savitz JB, Teague TK, Misaki M, Macaluso M, Wurfel BE, Meyer M, Drevets D, Yates W, Gleason O, Drevets WC, Preskorn SH (2018) Treatment of bipolar depression with minocycline and/or aspirin: an adaptive, $2 \times 2$ double-blind, randomized, placebo-controlled, phase IIA clinical trial. TransI Psychiatry 8(1):27. https://doi.org/10.1038/s41398-017-0073-7

37. Zhang L, An LT, Qiu Y, Shan XX, Zhao WL, Zhao JP, Li LH, Lang B, Wu RR (2019) Effects of Aspirin in Rats With Ouabain Intracerebral Treatment-Possible Involvement of Inflammatory Modulation? Front Psychiatry 10:497. https://doi.org/10.3389/fpsyt.2019.00497

38. Lee SY, Chen SL, Chang YH, Chen PS, Huang SY, Tzeng NS, Wang YS, Wang LJ, Lee IH, Wang TY, Yeh TL, Yang YK, Hong JS, Lu RB (2013) Inflammation's Association with Metabolic Profiles before and after a Twelve-Week Clinical Trial in Drug-Naïve Patients with Bipolar II Disorder. PLoS ONE 8(6):e66847. https://doi.org/10.1371/journal.pone.0066847

39. Dolsen MR, Soehner AM, Harvey AG (2018) Proinflammatory Cytokines, Mood, and Sleep in Interepisode Bipolar Disorder and Insomnia: A Pilot Study With Implications for Psychosocial Interventions. Psychosom Med 80(1):87-94. https://doi.org/10.1097/PSY.0000000000000529

40. Teixeira AL, Salem H, Frey BN, Barbosa IG, Machado-Vieira R (2016) Update on bipolar disorder biomarker candidates. Expert Rev Mol Diagn 16(11):1209-1220.

https://doi.org/10.1080/14737159.2016.1248413

41. Valvassori SS, Tonin PT, Dal-Pont GC, Varela RB, Cararo JH, Garcia AF, Gava FF, Menegas S, Soares JC, Quevedo J (2019) Coadministration of lithium and celecoxib reverses manic-like behavior and decreases oxidative stress in a dopaminergic model of mania induced in rats. Transl Psychiatry 9(1):297. https://doi.org/10.1038/s41398-019-0637-9

42. Dal-Pont GC, Resende WR, Bianchini G, Gava FF, Peterle BR, Trajano KS, Varela RB, Quevedo J, Valvassori SS (2019) Tamoxifen has an anti-manic effect but not protect the brain against oxidative stress in an animal model of mania induced by ouabain. J Psychiatr Res 113:181-189. https://doi.org/10.1016/j.jpsychires.2019.03.020

43. Varela RB, Resende WR, Dal-Pont GC, Gava FF, Tye SJ, Quevedo J, Valvassori SS (2020) HDAC inhibitors reverse mania-like behavior and modulate epigenetic regulatory enzymes in an animal model of mania induced by Ouabain. Pharmacol Biochem Behav 193:172917. https://doi.org/10.1016/j.pbb.2020.172917

44. Uyanik V, Tuglu C, Gorgulu Y, Kunduracilar H, Uyanik MS (2015) Assessment of cytokine levels and hs-CRP in bipolar I disorder before and after treatment. Psychiatry Res 228(3):386-392. https://doi.org/10.1016/j.psychres.2015.05.078 
45. de Sá Lima L, Kawamoto EM, Munhoz CD, Kinoshita PF, Orellana AM, Curi R, Rossoni LV, Avellar MC, Scavone C (2013) Ouabain activates NFKB through an NMDA signaling pathway in cultured cerebellar cells. Neuropharmacology 73:327-336.

https://doi.org/10.1016/j.neuropharm.2013.06.006

46. Chen Y, Huang W, Yang M, Xin G, Cui W, Xie Z, Silverstein RL (2017) Cardiotonic Steroids Stimulate Macrophage Inflammatory Responses Through a Pathway Involving CD36, TLR4, and Na/K-ATPase. Arterioscler Thromb Vasc Biol 37(8):1462-1469. https://doi.org/10.1161/ATVBAHA.117.309444

47. Elhaik E, Zandi $P$ (2015) Dysregulation of the NF-kB pathway as a potential inducer of bipolar disorder. J Psychiatr Res 70:18-27. https://doi.org/10.1016/j.jpsychires.2015.08.009

48. Bioque M, Mac-Dowell KS, Meseguer A, Macau E, Valero R, Vieta E, Leza JC, Bernardo M (2019) Effects of electroconvulsive therapy in the systemic inflammatory balance of patients with severe mental disorder. Psychiatry Clin Neurosci 73(10):628-635. https://doi.org/10.1111/pcn.12906

49. Clausen MV, Hilbers F, Poulsen $\mathrm{H}$ (2017) The Structure and Function of the Na,K-ATPase Isoforms in Health and Disease. Front Physiol 8:371. https://doi.org/10.3389/fphys.2017.00371

50. Wagoner JA, Dill KA (2019) Mechanisms for achieving high speed and efficiency in biomolecular machines. Proc Natl Acad Sci U S A 116(13):5902-5907. https://doi.org/10.1073/pnas.1812149116

\section{Figures}

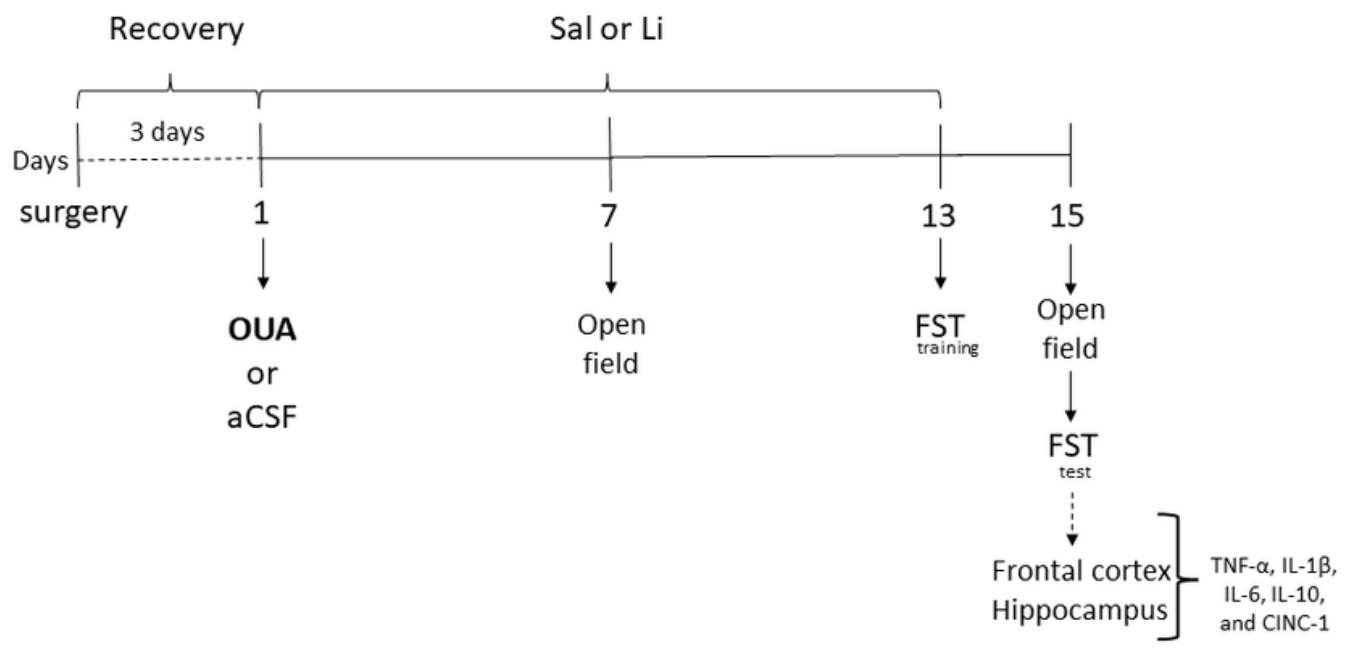

Figure 1 
Schematic representation of the experimental design of present study. (Abbreviations: aCSF: artificial cerebrospinal fluid; CINC-1: cytokine-induced neutrophil chemoattractant 1; ICV: intracerebroventricular; IL13: interleukin 13; IL-6: interleukin 6; IL-10: interleukin 10; Li: lithium; OUA: ouabain; Sal: saline; TNF-a: tumor necrosis factor $\alpha$ )
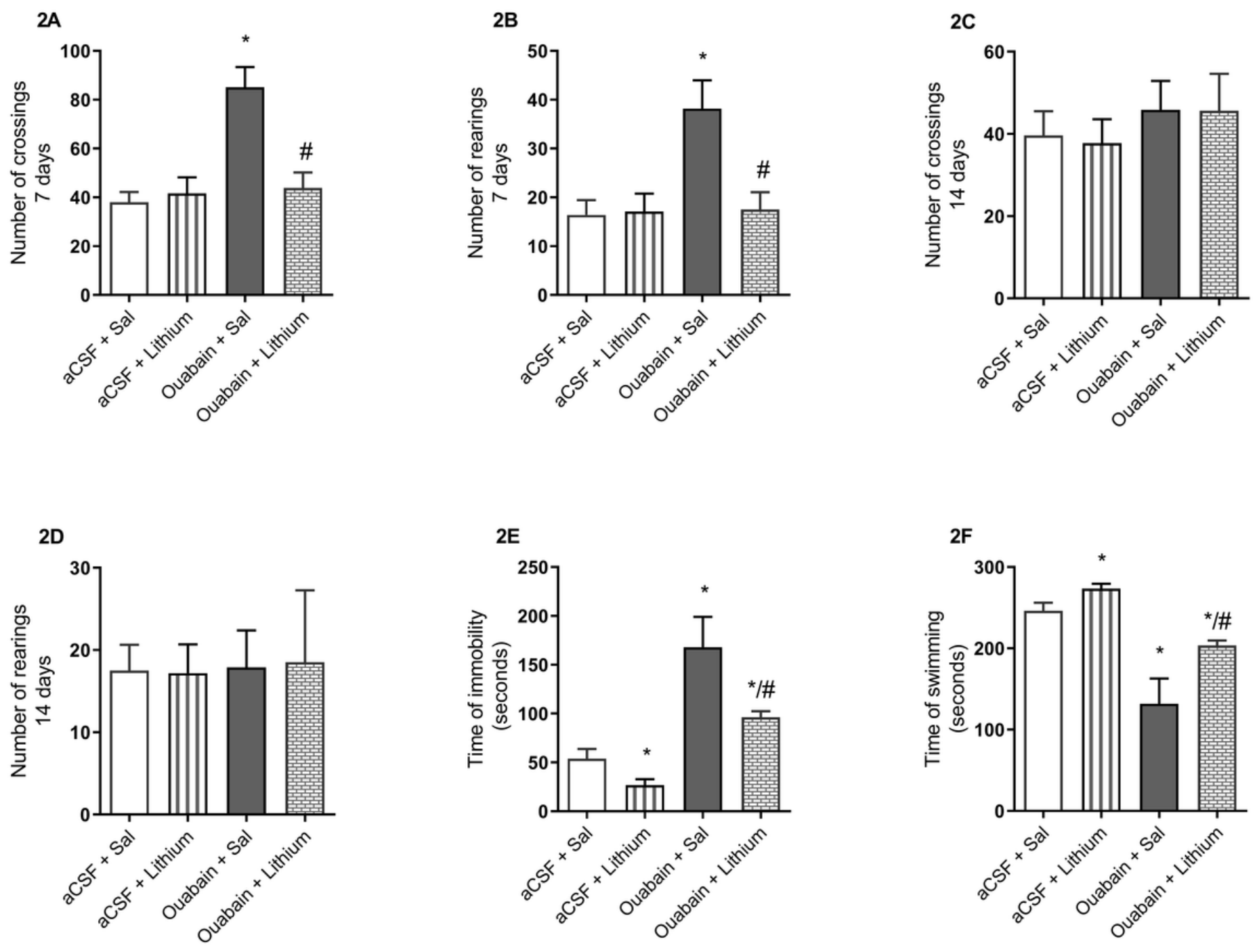

Figure 2

Effect of the intracerebroventricular (ICV) administration of ouabain (OUA) on the behavioral parameters of the open field (2A-2D) and forced swimming (2E-2F) tests in adult male Wistar rats ( $n=8$ per group). Animals were subjected to the assessments seven and 14 days following OUA infusion. Data were analyzed by two-way analysis of variance followed by Tukey's test when $p$ was significant. Values are expressed as mean \pm standard error of the mean (arbitrary units or time, in seconds [s]). ${ }^{*} p \leq 0.05$, as compared to aCSF + saline (Sal) group; $\# p \leq 0.05$, as compared to OUA + Sal group 

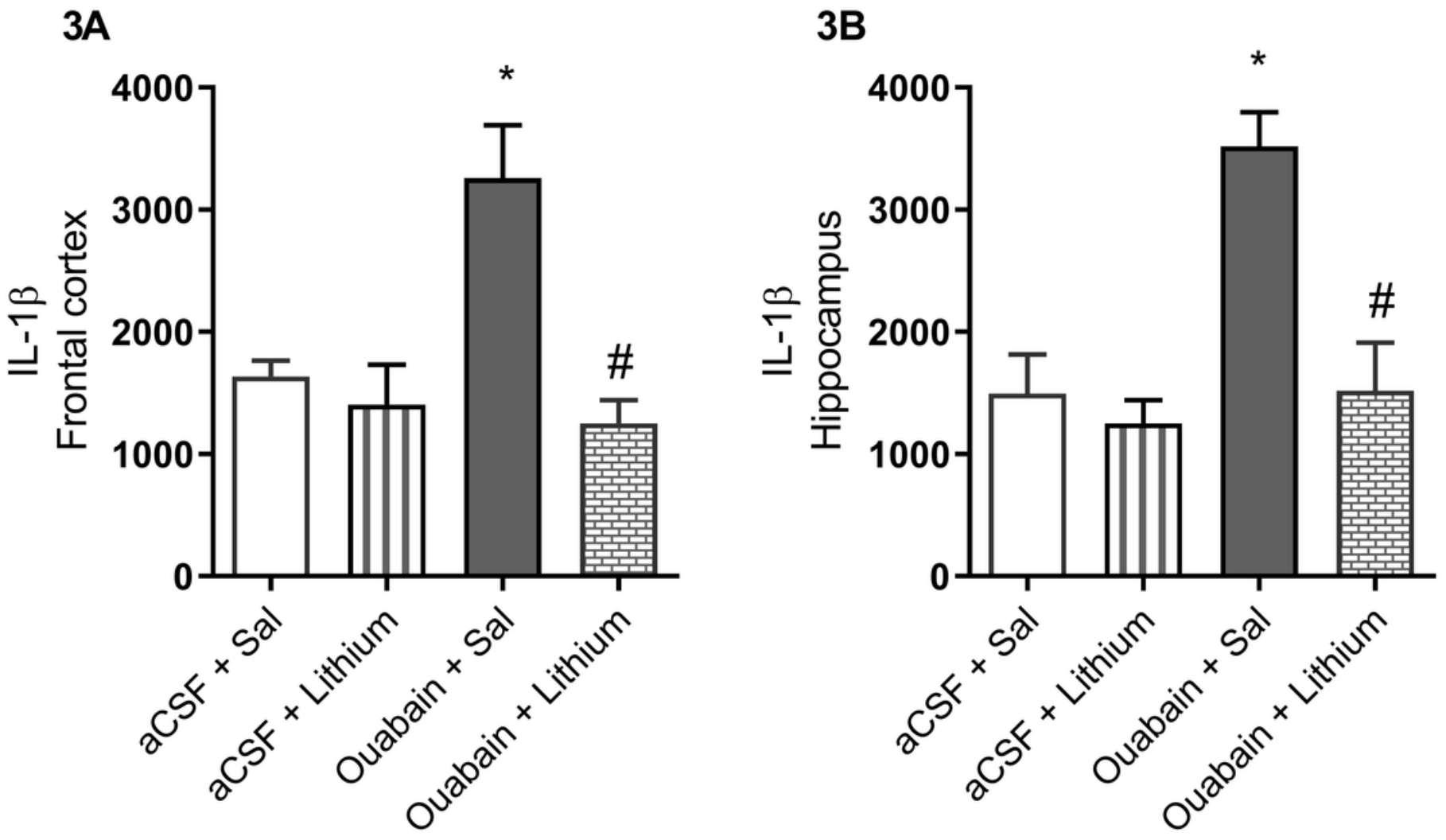

Figure 3

Effect of the intracerebroventricular (ICV) administration of ouabain (OUA) on the levels of interleukin $1 \beta$ (IL-1 $\beta$ ) in the frontal cortex (3A) and hippocampus (3B) of adult male Wistar rats ( $n=8$ per group).

Animals were subjected to the assessments 14 days following OUA infusion. Data were analyzed by twoway analysis of variance followed by Tukey's test when $p$ was significant. Values are expressed as mean \pm standard error of the mean (picograms per 100 milligrams [pg/100 mg] tissue). ${ }^{\star} p \leq 0.05$, as compared to aCSF + saline (Sal) group; $\# p \leq 0.05$, as compared to OUA + Sal group 


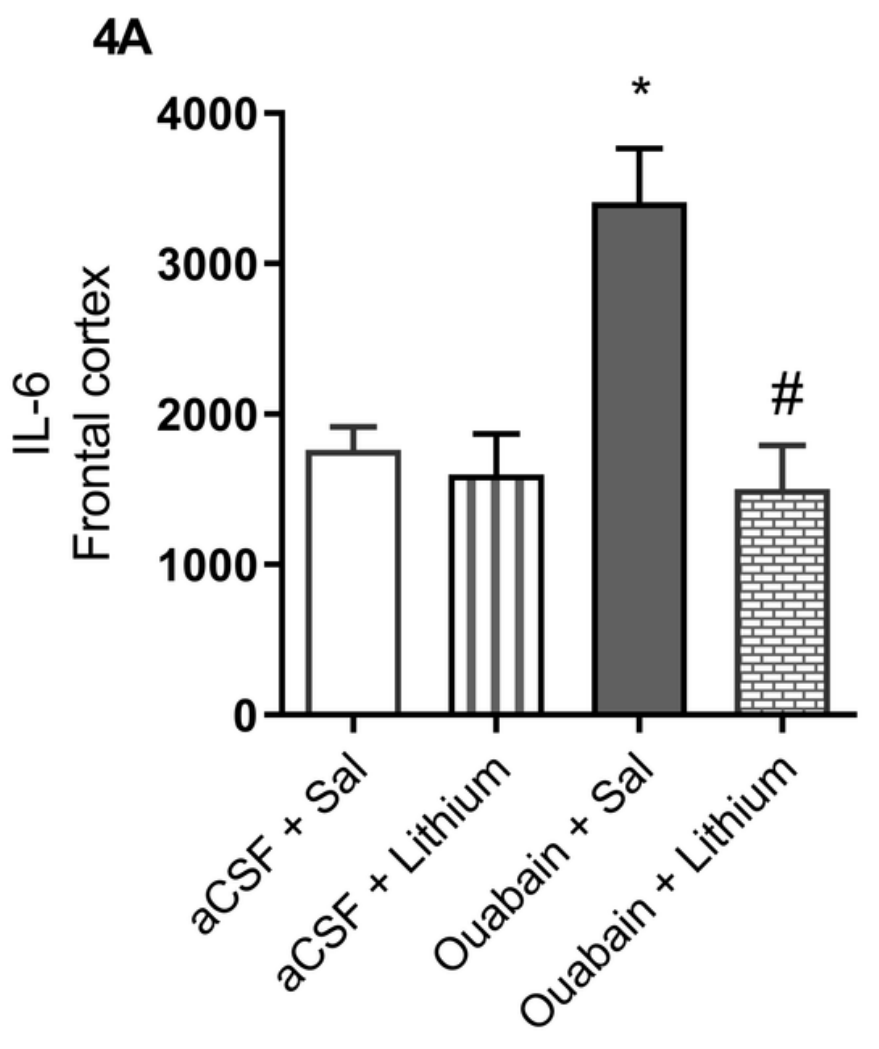

4B

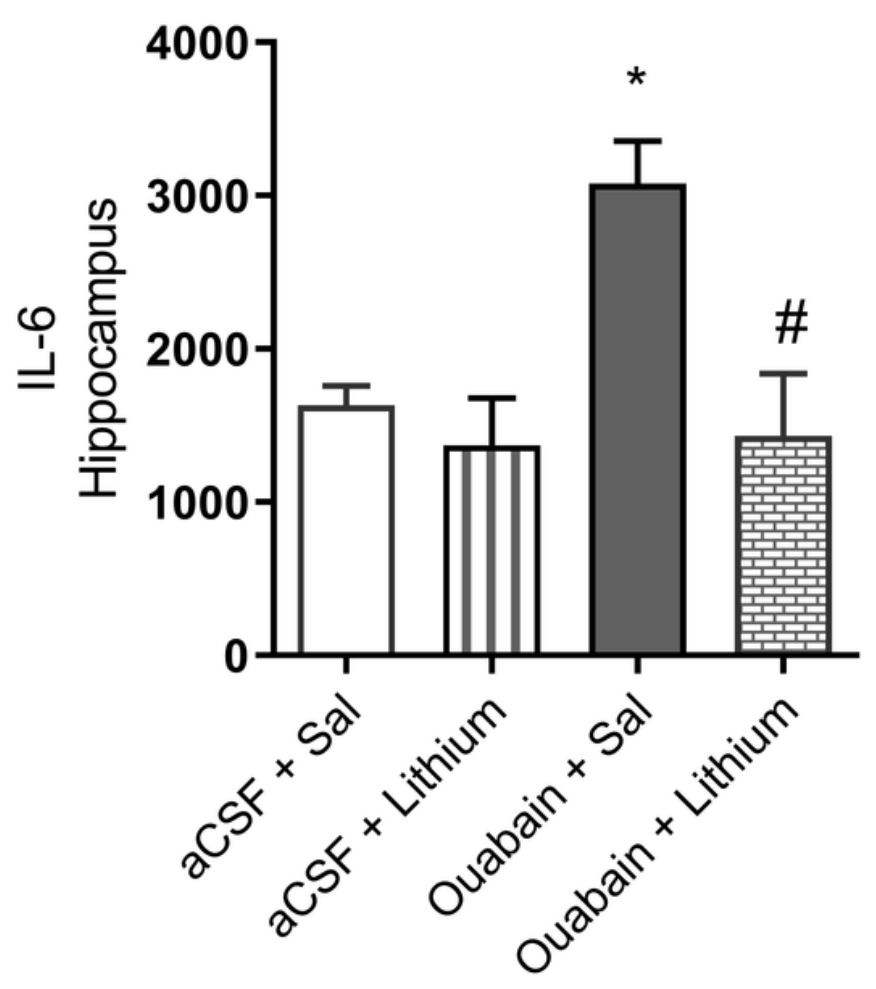

Figure 4

Effect of the intracerebroventricular (ICV) administration of ouabain (OUA) on the levels of interleukin 6 (IL-6) in the frontal cortex (4A) and hippocampus (4B) of adult male Wistar rats ( $n=8$ per group). Animals were subjected to the assessments 14 days following OUA infusion. Data were analyzed by two-way analysis of variance followed by Tukey's test when $p$ was significant. Values are expressed as mean \pm standard error of the mean (picograms per 100 milligrams [pg/100 mg] tissue). ${ }^{*} p \leq 0.05$, as compared to aCSF + saline (Sal) group; $\# p \leq 0.05$, as compared to OUA + Sal group 
$5 \mathrm{~A}$

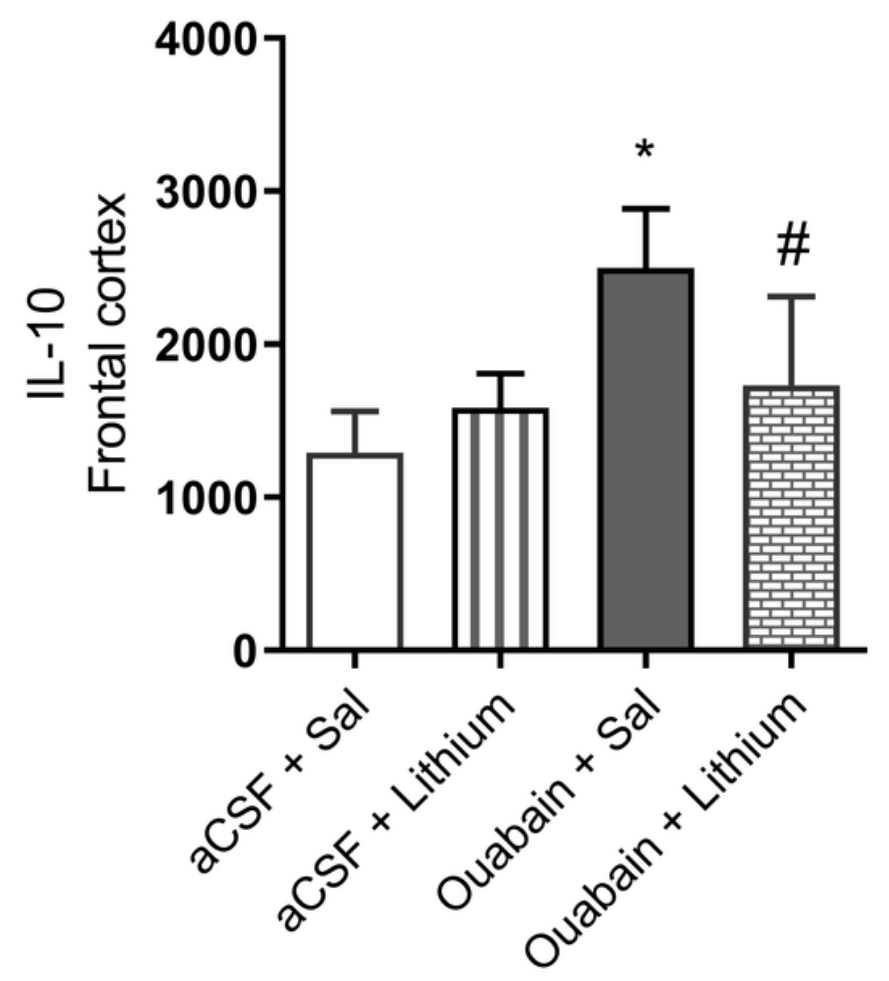

$5 \mathrm{~B}$

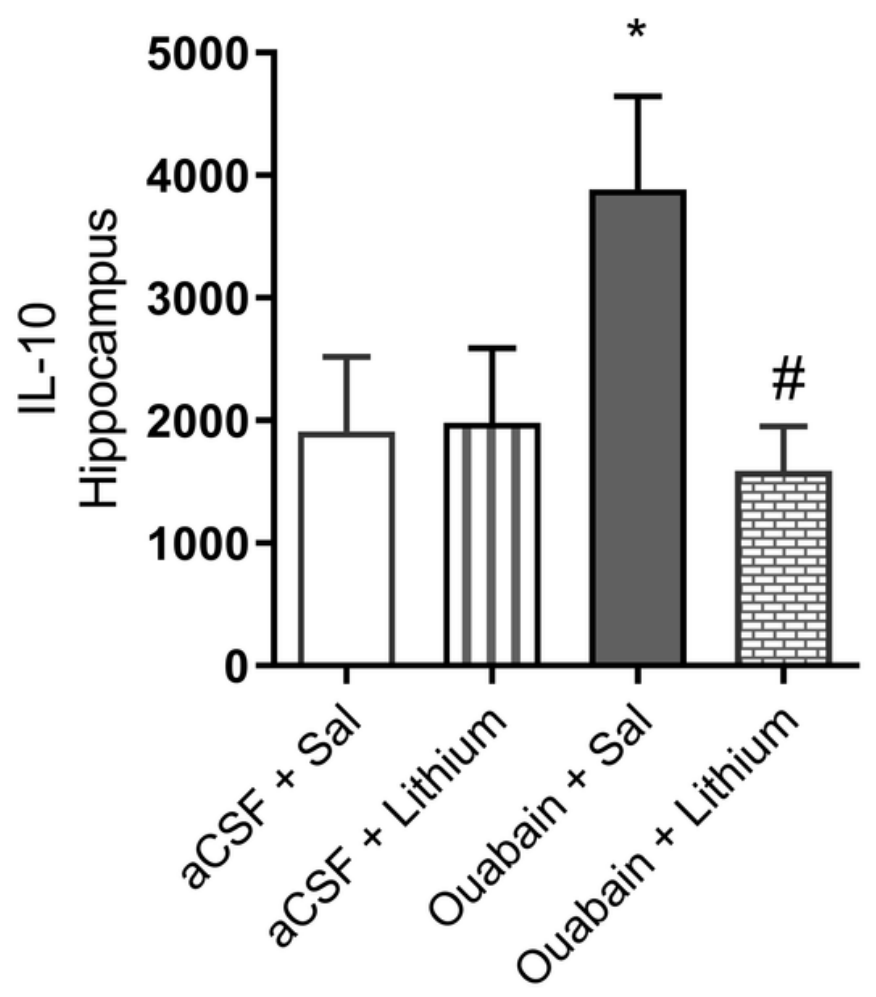

Figure 5

Effect of the intracerebroventricular (ICV) administration of ouabain (OUA) on the levels of interleukin 10 (IL-10) in the frontal cortex (5A) and hippocampus (5B) of adult male Wistar rats ( $n=8$ per group).

Animals were subjected to the assessments 14 days following OUA infusion. Data were analyzed by twoway analysis of variance followed by Tukey's test when $p$ was significant. Values are expressed as mean \pm standard error of the mean (picograms per 100 milligrams $[\mathrm{pg} / 100 \mathrm{mg}]$ tissue). ${ }^{\star} p \leq 0.05$, as compared to aCSF + saline (Sal) group; $\# p \leq 0.05$, as compared to OUA + Sal group 

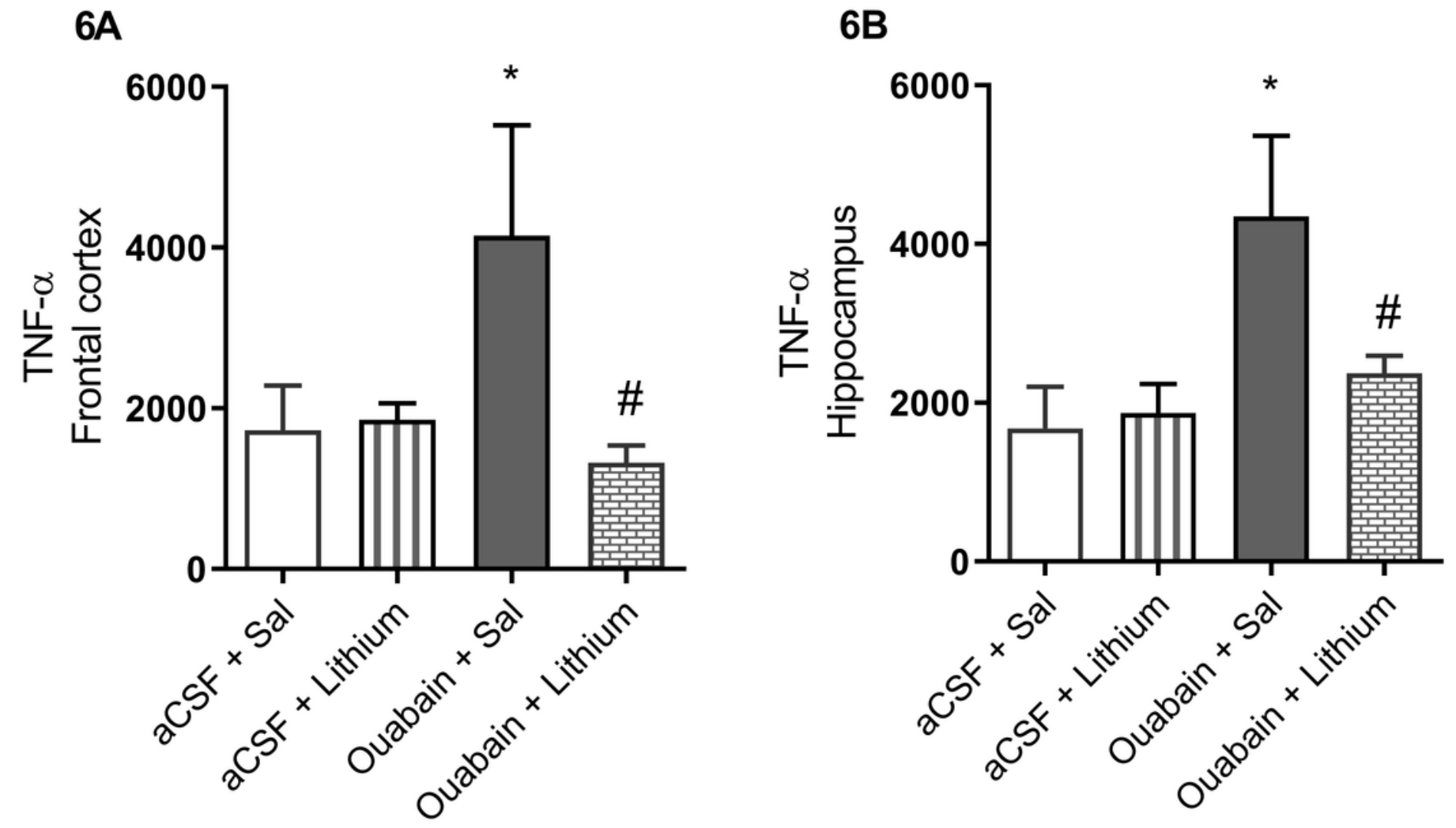

\section{Figure 6}

Effect of the intracerebroventricular (ICV) administration of ouabain (OUA) on the levels of the tumor necrosis factor a (TNF-a) in the frontal cortex (6A) and hippocampus (6B) of adult male Wistar rats $(n=8$ per group). Animals were subjected to the assessments 14 days following OUA infusion. Data were analyzed by two-way analysis of variance followed by Tukey's test when $p$ was significant. Values are expressed as mean \pm standard error of the mean (picograms per 100 milligrams [pg/100 mg] tissue). * $p$ $\leq 0.05$, as compared to aCSF + saline (Sal) group; $\# p \leq 0.05$, as compared to OUA + Sal group 


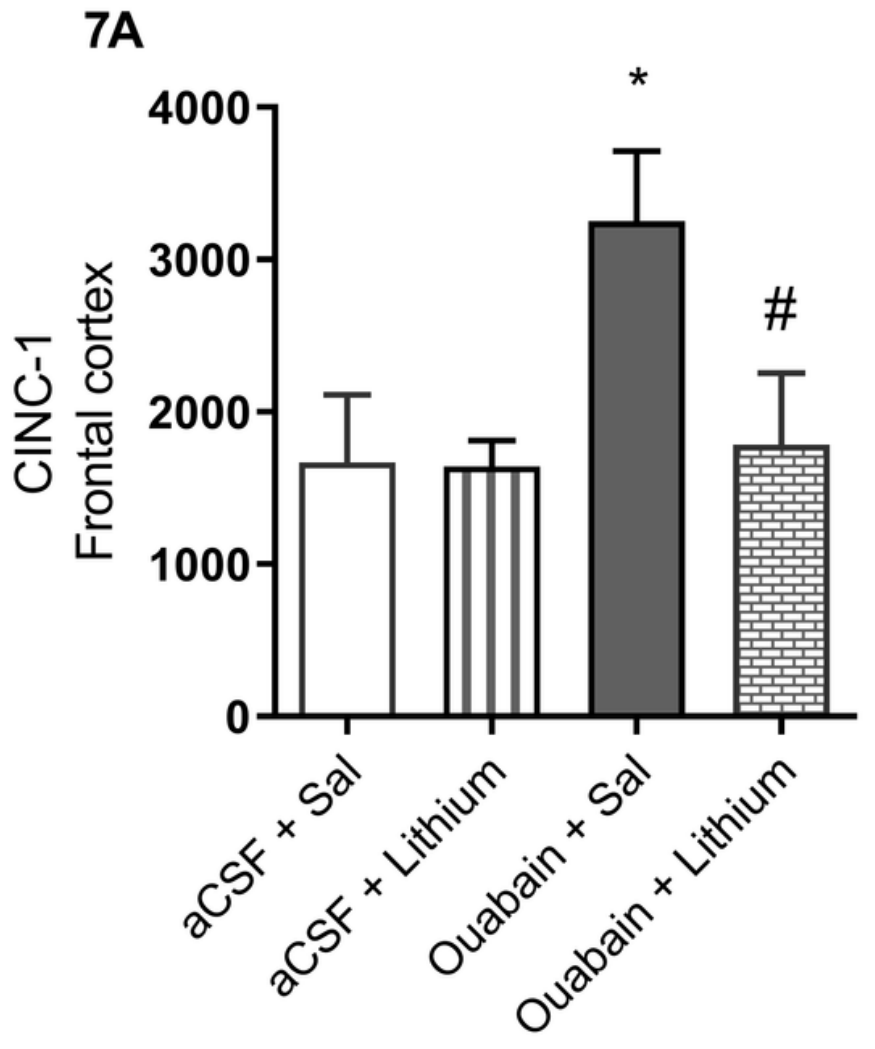

7B

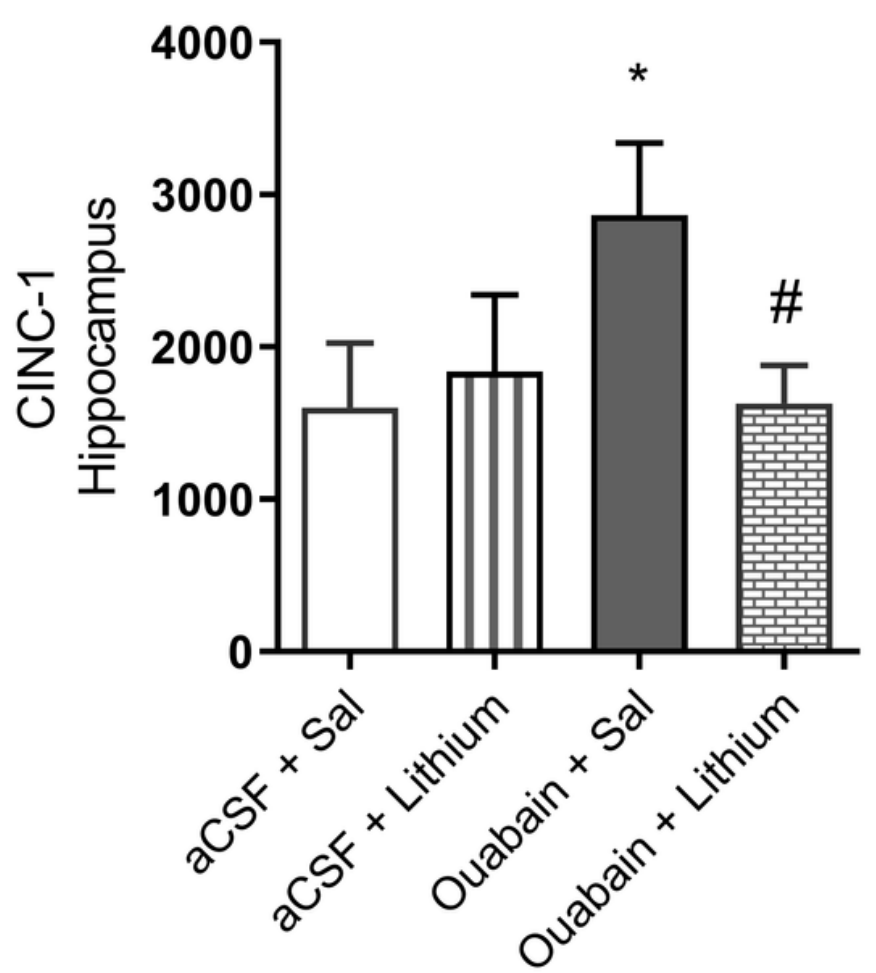

Figure 7

Effect of the intracerebroventricular (ICV) administration of ouabain (OUA) on the levels of the cytokineinduced neutrophil chemoattractant 1 (CINC-1) in the frontal cortex (7A) and hippocampus (7B) of adult male Wistar rats ( $n=8$ per group). Animals were subjected to the assessments 14 days following OUA infusion. Data were analyzed by two-way analysis of variance followed by Tukey's test when $p$ was significant. Values are expressed as mean \pm standard error of the mean (picograms per 100 milligrams [pg/100 mg] tissue). ${ }^{*} p \leq 0.05$, as compared to aCSF + saline (Sal) group; $\# p \leq 0.05$, as compared to OUA + Sal group 